\title{
JEJUNAL DUPLICATION CYST COMMUNICATING WITH THE COMMON BILE DUCT
}

\author{
Sumana B. S1, Visweswara R. N², Ramesh Reddy G³
}

HOW TO CITE THIS ARTICLE:

Sumana B. S, Visweswara R. N, Ramesh Reddy G. "Jejunal Duplication CYST Communicating with the Common Bile Duct”. Journal of Evolution of Medical and Dental Sciences 2015; Vol. 4, Issue 51, June 25; Page: 8961-8966, DOI: $10.14260 /$ jemds/2015/1301

\begin{abstract}
Jejunal duplication is a rare congenital anomaly of unclear etiology. It may communicate with the adjacent normal bowel. However, communication with common bile duct has not been described. Herein we report a case of jejunal duplication that communicated with the common bile duct in a 12 year old girl who presented with intestinal obstruction. Exploratory laparotomy findings were interpreted as huge choledochal cyst adherent to proximal jejunum. Excision of the cyst and proximal jejunum to which it was adherent was curative. After histopathologic evaluation and subsequent literature review for type II choledochal cyst with its etiopathologic considerations, the present case conforms to the diagnosis of jejunal duplication with communication to the common bile duct, the communication possibly being a congenital type. Such rare anomalies posing diagnostic and therapeutic challenge should be considered in the differential diagnoses of cystic abdominal lesions.

KEYWORDS: Alimentary tract duplication, Jejunum, Common bile duct, Duplication cyst.
\end{abstract}

INTRODUCTION: Alimentary tract duplications (ATD) are rare (1 in 4500), congenital lesions that can occur anywhere from the mouth to the anus and the nearby organs.[1,2,3] In the entire ATD's jejunal duplications account for $10 \% .{ }^{[4]}$ ATD's present with wide spectrum of symptoms and nonspecific signs, making clinical diagnosis difficult, ${ }^{[2]}$ final diagnosis based on surgical observation and histopathological study.[3] Pathologically ATD's can be spherical or tubular and may or may not be communicating with the adjacent bowel segment. ${ }^{[4]}$ Duplications sometimes communicate with other organs.[5,6] We report a rare case of jejunal duplication cyst communicating with the common bile duct (CBD) in a 12 year old girl who presented with clinical features of intestinal obstruction. This diagnosis was arrived by operative findings and subsequent histopathologic examination. Further we reviewed the literature for a better understanding of this rare abnormality.

CASE REPORT: A 12-yrs old female presented with distension of abdomen since birth, accompanied with occasional episodes of non-projectile, non-bilious vomiting for the past 10 -yrs and abdominal pain for the past three years. Her weight was $26 \mathrm{~kg}$. Complete blood count and serum electrolytes were within normal limits. Vital parameters were stable. There was no icterus. On inspection, abdomen was found distended, umbilicus everted, central in position. No tenderness, no shifting dullness, no hepatosplenomegaly on palpation. Her abdominal girth was $69 \mathrm{~cm}$. On auscultation bowel sounds were heard occasionally.

Ultrasonography of abdomen revealed grossly dilated stomach. A plain x-ray of the abdomen showed erect-fundal shadow superadded with intestinal shadow. No fluid levels noted. A barium meal follow-through examination done subsequently revealed normal stomach and duodenum (no evidence of obstruction). Her clinical and radiological findings were suggestive of subacute intestinal obstruction. 
Further investigation could not be carried out, as the patient presented with an acute abdomen. She underwent exploratory laparotomy which showed a huge fluid-filled cyst occupying whole of the abdomen up to pelvis. Part of the cyst was adherent to proximal jejunum, and there was a narrow communication with the supraduodenal third of the common bile duct. Portion of the cyst was seen adherent to proximal jejunum. The gall bladder was distended; the ascending colon was congenitally not fixed to the retroperitoneum. Excision of the cyst was done followed by resection of proximal jejunum to which it was adherent and duodenojejunal, choledeocho-jejunal and jejunojejunal anastomoses. Recovery of the patient was uneventful. An esophago-gastro-duodenoscopy done twenty days postoperative revealed a normal study.

With the operative differential diagnoses of choledochal cyst and mesenteric cyst, the resected tissue was submitted to pathology department. The specimen measured about $26 \times 10 \times 10 \mathrm{~cm}$ and consisted of an elongated cystic swelling with segment of intestine measuring $13 \mathrm{~cm}$ in length stretched over one of the surface. The proximal end (as per the surgical notes) was tied with sutures and the distal end with attached intestine was blind; a constriction was noted between the proximal portion and distal portion of the cyst [Figure 1A]. Specimen exuded more than two liters of relatively thick bile stained fluid and the cavity showed no communication between intestine and cyst, but they were sharing common muscular wall. The inside of the cyst revealed a shelf-like ridge corresponding to the outer constriction between two portions of the cyst and patchy areas of thickening and elevation more so in the constriction between proximal and distal portion of the cyst. The inner surface had an appearance of dilated intestinal segment, mucosal pattern being appreciated focally. The native intestinal mucosa appeared unremarkable [Figure 1B].

Histopathologic evaluation of representative sections was carried out. Common wall between intestine and cyst showed single common muscularis propria i.e fusion between muscularis propria of duplication and that of normal bowel. Sections from the native intestine showed histologic structure of jejunum. The cyst wall comprised jejunal epithelium with extensive squamous metaplasia and foci of ectopic gastric type epithelium [Figure 2A, 2B]. Sections from the proximal portion of the cyst revealed gastrointestinal (GI) epithelium with squamos metaplasia [Figure 3]. No dysplasia/malignancy in any of the sections. Correlating the histopathologic findings with surgical observations, diagnosis of jejunal duplication cyst communicating with CBD was offered.

DISCUSSION: In 1733, Calder published the first report of an intestinal duplication. In 1937, W.E. Ladd used the phrase "duplications of the alimentary tract". [7] Duplications at all levels of GI tract share similarities in their pathologic features, but no single existing etiologic theory can satisfactorily explain all duplications in all segments of the alimentary tract.[1,2,4,8] Hypotheses to explain duplications include persistence of embryonic diverticula, fusion of embryologic longitudinal folds, abortive twinning, intrauterine intestinal ischemia, and sequestration of embryonic tissues during embryonic movements. ${ }^{[1,3,4,9]}$ Among all the hypothesis, a popular theory which adequately explains duplications of esophagus, small bowel and colon is the "aberrant luminal recanalization theory".[1,4]

The most common site is the ileum, followed by esophagus, large bowel, jejunum, stomach, and duodenum. ${ }^{[4]}$ Thirty four patients in a series of 78 GI tract duplications had small bowel duplications of which only six were jejunal in origin.[7] Duplications primarily manifest in their first year of life.[2,3,4,10] However they may not be symptomatic until at school age or adulthood.[2,10] ATD's are congenital lesions, spherical or tubular in shape, may communicate with the lumen, $[1,2,3,4]$ may be multiple ${ }^{[4,7]}$ and there may be co-existence of cystic and tubular duplications in single individual.[10] 
The spheric cysts are more common with no communication while tubular are less common and communicate with the adjacent GI tract lumen.[1,4,8] A study of six ATD's includes one case of noncommunicating jejunal duplication of $7 \times 6 \mathrm{~cm}$ in size in a 11 year old male presenting with abdominal pain of five days duration. ${ }^{[10]}$ In our case, the jejunal cyst was not communicating with the native lumen but communicated with CBD with distension of the duplication cyst by thick bilious fluid causing pressure on the adjacent bowel. Thus she manifested with intestinal obstruction, one of the various obscure clinical features of ATD's. ${ }^{[1,2,10]}$ Out of 27 patients with ATD's all four patients with jejunal duplication presented with bowel obstruction.[8] As mentioned in some reports[2,10] conventional radiology did not allow accurate diagnosis in our case and this created a challenge intraoperatively.

The three criteria for the diagnosis of duplication are the presence of an intimate attachment to the GI tract, a smooth muscle coat, and an alimentary mucosal lining. Of these criteria, only the presence of a smooth muscle coat is absolutely necessary to define duplication. ${ }^{[9]}$ The present case on histopathology satisfied the pathologic criteria for duplication. Microscopically the GI tract duplications are lined with mucosa not necessarily that of the adjacent GI tract.

They may contain heterotopic tissues including thyroid stroma, pancreas, gastric mucosa, lymphoid aggregates resembling Peyer's patches, ciliated bronchial epithelium, lung tissue and cartilage. ${ }^{[9]}$ Gastric mucosa and pancreatic tissue are the clinically significant ectopic tissues found in ATD's ${ }^{[1,2,4]}$ Thus these duplications are named according to the segment to which they lie adjacent. ${ }^{[4,5]}$

The presence of gastric mucosa predisposes the patient to ulceration that can progress to haemorrhage and perforation. ${ }^{[1,7,8]}$ Jejunal duplications are commonly located at the mesenteric border, and thus easily mistaken for mesenteric or omental cysts.[8] This was clarified in our case by identification of a mucosal rather than endothelial lining.

Duplications sometimes communicate to sites other than the lumen of GI tract, adjacent to which it lies. Gastric duplication communicating with the left hepatic duct and duodenal duplication communicating with the CBD are reported. ${ }^{[5,6]}$ However jejunal duplication cyst communicating with the CBD as in our case is not described.

Intra-operatively our case posed to be a choledochal cyst. Modified classification of bile duct cysts proposed by Todani and colleagues describes Type II as a saccular diverticulum of CBD, etiopathogenesis of which is being debated as biliary duplication or acquired inflammatory diverticulum[11,12] Duplication of CBD is an extremely rare congenital anomaly, the modified Choi et al classification of which is based on the morphology of the duplicated bile duct.[13] The type II is described as bifurcation of the distal bile duct and each channel draining independently into different parts of upper GI tract.[13] Our case also has same morphology as type II but the drainage of the accessory channel is into the jejunal duplication.

In our case the histology of proximal connecting portion of the cyst showed the same structure seen in the jejunal duplication; similar to that noted by Kaneko $\mathrm{K}$ et al.[5] In this regard our opinion is to consider the pathology in our case as a huge jejunal duplication cyst having a congenital communication with the common bile duct; however a satisfactory explanation to this occurrence is difficult.

CONCLUSION: This case of jejunal duplication cyst communicating with CBD, the type of communication being possibly a congenital type is a rare abnormality probably not reported in the literature. Awareness of the varied presentations of duplication cysts would help in appropriate 
management during surgery without confusion and also guides to a precise final diagnosis on histopathology. Duplication although rare, is a curable cause of GI symptoms and should be considered in the differential diagnoses of any abdominal mass lesion in children.

\section{REFERENCES:}

1. Mayer JP, Bettoli M. Alimentary tract duplications in newborns and children: Diagnostic aspects and the role of laparoscopic treatment. World J Gastroenterol. 2014; 20(39): 14263-71.

2. Olajide ARL, Yisau AA, Abdulraseed NA, Kashim IO, Olaniyi AJ, Morohunfade AO. Gastrointestinal duplications: Experience in seven children and a review of the literature. Saudi J Gastroenterol. 2010 Apr; 16 (2): 105-9.

3. Zouari M, Bouthour H, Abdallah RB, Hlel Y, Malek RB, Gharbi Y, et al. Alimentary tract duplications in children: Report of 16 years' experience. Afr J Paediatr Surg 2014; 11: 330-3.

4. Macpherson RI. Gastrointestinal tract duplications: clinical, pathologic, etiologic, and radiologic considerations. Radiographics. 1993; 13: 1063-80.

5. Kaneko K, Ando H, Watanabe Y, Seo T, Harada T, and Ito F. Gastric Duplication Communicating With the Left Hepatic Duct: A Rare Case of Recurrent Hemobilia in a Child. J Pediatr Surg 1999; 34(10): 1539-40.

6. Koffie RM, Lee S, Perez-Atayde A, Mooney DP. Periampullary duodenal duplication cyst masquerading as a choledochocele. Pediatr Surg Int. 2012; 28 (10): 1035-9.

7. Bower RJ, Sieber WK, and Kiesewetter WB. Alimentary tract duplications in children. Ann Surg. 1978; 188(5): 669-74.

8. Iyer CP, and Mahour GH. Duplications of the Alimentary Tract in Infants and Children. J Pediatr Surg. 1995; 30(9): 1267-70.

9. The Nonneoplastic Small Intestine. In: Fenoglio-Preiser CM, Noffsinger AE, Stemmermann GN, Lantz PE, Isaacson PG, editor. Gastrointestinal Pathology an Atlas and Text. $3^{\text {rd }}$ ed. Philadelphia: Lippincott Williams and Wilkins; 2008. p. 306-9.

10. Choi SO, Park WH, Kim SP. Enteric Duplications in Children - an analysis of 6 cases. J Korean Med Sci. 1993; 8 (6): 482-7.

11. Bhavsar MS, Vora HB, Giriyappa VH. Choledochal cysts: A review of literature. Saudi J Gastroenterol 2012; 18: 230-6.

12. Mesleh M, Deziel DJ. Bile Duct Cysts. Surg Clin N Am 2008; 88: 1369-84.

13. Arora A, Sureka B, Kasana V, Patidar Y, Bansal K. Common bile duct duplication: The more the murkier. Saudi J Gastroenterol 2015; 21: 51-4. 


\section{BRIEF COMMUNICATION}

Figure 1A: Gross unopened specimen of the excised cystic swelling on the mesenteric aspect of the small intestinal segment.

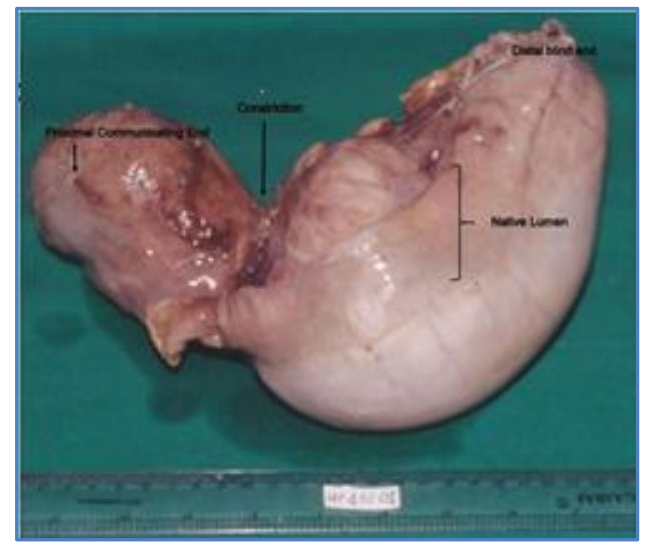

Fig. 1 A

Figure 1B: Same specimen with cut open native GI lumen.

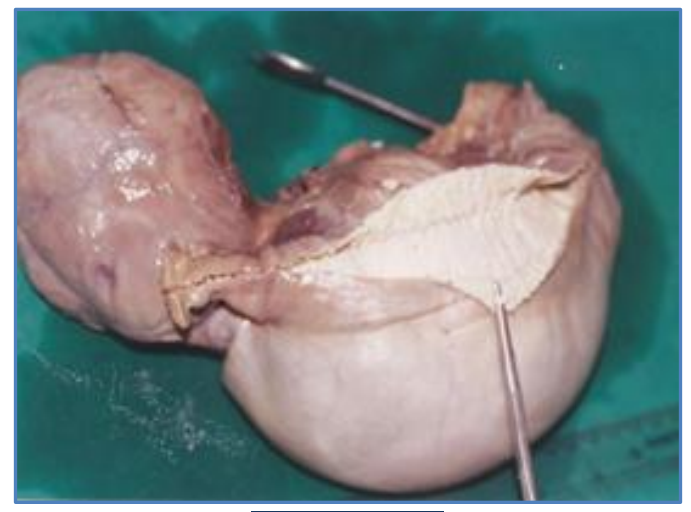

Fig. 1B

Figure 2A: Histology of the duplication cyst showing two mucosal layers. The cyst wall lined by ectopic gastric type epithelium shares its smooth muscle wall with the native small intestine (Jejunal epithelium). H \& E stain, 40x.

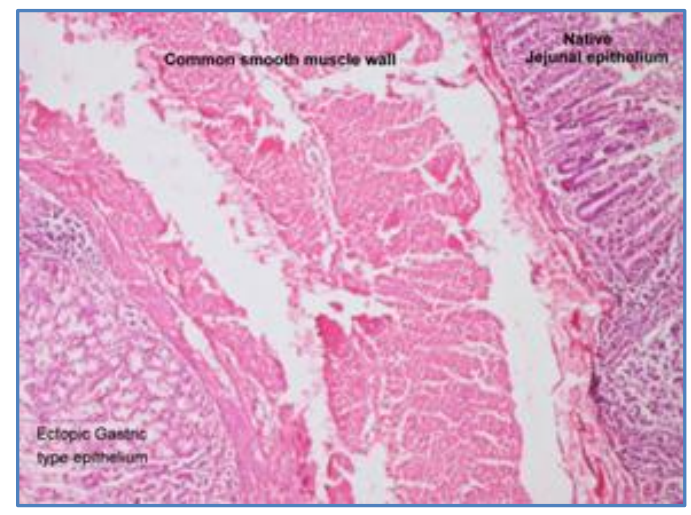

\section{Fig. 2A}




\section{BRIEF COMMUNICATION}

Figure 2B: Cyst wall with atrophic GI mucosa transition to squamous metaplastic epithelium, shares muscle wall with native jejunum. $\mathrm{H} \& \mathrm{E}$ stain, 40x.

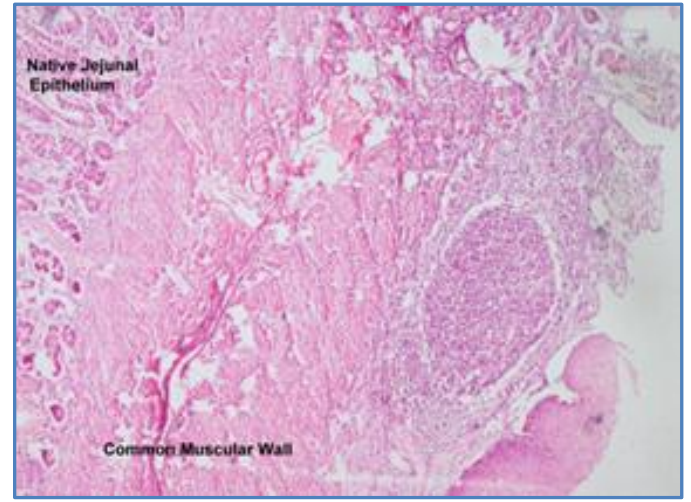

\section{Fig. 2B}

Figure. 3: Histology of the proximal free cyst wall shows GI epithelium with squamous metaplasia. $\mathrm{H}$ \& E stain, 40x.

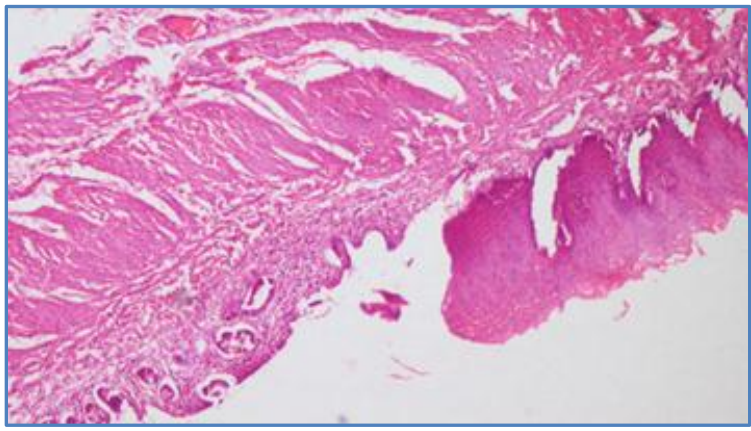

\section{Fig. 3}

\section{AUTHORS:}

1. Sumana B.S.

2. Visweswara R. N.

3. Ramesh Reddy G.

\section{PARTICULARS OF CONTRIBUTORS:}

1. Associate Professor, Department of Pathology, Vydehi Institute of Medical Sciences and Research Center, Bangalore.

2. Consultant Pathologist, Department of Pathology, PDH Sindhi Hospital, Bangalore.

3. Professor and HOD, Department of General Surgery, Vydehi Institute of Medical Sciences and Research Center, Bangalore.

\section{NAME ADDRESS EMAIL ID OF THE CORRESPONDING AUTHOR:}

Dr. Sumana B. S, \#15, Renuka, $9^{\text {th }}$ Main, $11^{\text {th }}$ Cross, BDA Layout, HAL $3^{\text {rd }}$ Stage, Jeevanbhimanagar, Bangalore-560075.

E-mail: sumana.devanand@gmail.com

Date of Submission: 02/06/2015.

Date of Peer Review: 03/06/2015.

Date of Acceptance: 17/06/2015.

Date of Publishing: 25/06/2015.

FINANCIAL OR OTHER COMPETING INTERESTS: None 